\title{
Editorial
}

\section{Mutilación genital femenina ¿práctica cultural o violencia de género? Realidad en la Comunidad Valenciana}

\author{
María Vizcaíno Gómez \\ Médico Especialista en Ginecología y Obstetricia. Hospital Universitario Vinalopó, Elche. \\ Cómo citar esta editorial en edición digital: Vizcaíno Gómez, $M^{a}$. (2018). Mutilación genital femenina ¿Práctica cultural o \\ violencia de género? Realidad en la Comunidad Valenciana. Cultura de los Cuidados (Edición digital), 22(50). \\ Recuperado de http://dx.doi.org/10.14198/cuid.2018.50.01. \\ Correspondencia: Remitirse al correo electrónico. \\ Correo electrónico: mvizcaino@vinaloposalud.com \\ Recibido-Aceptado: editorial (autores invitados).
}

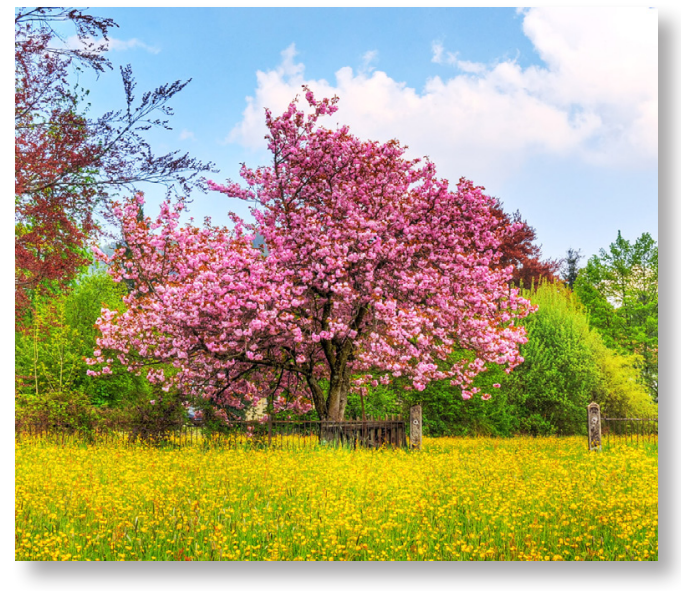

ABSTRACT

This editorial describes the characteristics and classes of Female Genital Mutilation and its incidence in Spain, especially in the Valencian Community.

Keywords: Female genital mutilation, gender violence, nursing.

\section{RESUMEN}

En esta editorial se describen las características y clases de la Mutilación Genital Femenina y su incidencia en España, especialmente en la Comunidad Valenciana.

Palabras clave: Mutilación Genital Femenina, violencia de género, enfermería.

\section{RESUMO}

Este editorial descreve as características e classes da Mutilação Genital Feminina e sua incidência na Espanha, especialmente na Comunidade Valenciana.

Palavras-chave: Mutilação genital feminina, violência de gênero, enfermagem.

Millones de mujeres sufren mutilación de sus órganos genitales. Millones de mujeres quedan así marcadas para el resto de la vida... Se calcula que más de 125 millones de mujeres y niñas han sido mutiladas y 30 millones de niñas se podrían encontrar en situación de riesgo de sufrir esta práctica en las próximas décadas.

Según la OMS se considera Mutilación genital femenina ( MGF) a todos aquellos procedimientos que de forma intencional y por motivos no médicos lesionan los órganos genitales femeninos, sin que esto aporte ningún beneficio a la salud de mujeres y niñas sino que les perjudica de forma muy variada. Es practicada casi siempre en menores y reconocida internacionalmente como una violación de los derechos humanos de las mujeres y niñas. Refleja una desigualdad entre los sexos y cons- 
tituye una forma extrema de discriminación de la mujer y la violación de los derechos del niño, los derechos a la salud, la seguridad y la integridad física, el derecho a no ser sometido a torturas y tratos crueles, inhumanos o degradantes e incluso en aquellos casos en los que las consecuencias son fatales, del derecho a la vida.

Existen definidos 4 tipos en función de la radicalidad de la excisión así como de si llevan asociados procedimientos de cierre del introito vaginal ( infibulación) que, a su vez conlleva maniobras de reapertura para posibilitar las relaciones sexuales o el parto (desinfibulación) y posteriormente el nuevo cierre del introito durante el puerperio (Reinfibulación). Se contemplan también otros procedimientos lesivos de los genitales externos con fines no médicos, tales como la perforación, incisión, anillado, raspado o cauterización de la zona genital, introducción de corrosivos en vagina... En la práctica clínica las mutilaciones tipo I y II son las más comunes y suelen constituir entre el $80 \%$ y el $85 \%$ de los casos. La tipo III constituye $15-20 \%$ de los casos (es el más practicado en Somalia, el norte del Sudán y Djibouti) pero hay que tener en cuenta que cada etnia / partera tiene su "técnica propia" para realizar la mutilación (sin formación alguna) por lo que no encontramos tipos claros y concretos de mutilación sino pacientes con mas o menos lesión funcional.

Dentro de las causas o "justificaciones" de esta práctica encontramos diversos factores culturales, religiosos, sociales y comunitarios. Su realización tiende a perpetuarse por la presión social y por adaptarse a lo que se ha venido haciendo tradicionalmente, obedeciendo a una cuestión de coherencia de grupo y suponiendo en muchos casos un requisito ineludible para poder casarse, para conseguir una determina posición social o simplemente para ser aceptada en la comunidad. Existe la creencia de que fomenta la castidad y mitiga el deseo sexual con lo que garantiza la fidelidad dentro de la pareja, mejora la fertilidad e incluso el parto, protege al recién nacido ya que el contacto con el clítoris en el momento del parto puede poner en peligro su vida. Los genitales externos resultan carentes de belleza si son voluminosos y las mujeres no mutiladas se consideran sucias por lo que se les llega a prohibir la manipulación de agua y alimentos. La mutilación suele estar realizada por personas mayores de la comunidad (normalmente mujeres, pero no únicamente) o parteras tradicionales. En determinados pueblos pueden realizarla curanderos, barberos, miembros de sociedades secretas, herboristas o una pariente en lugares clandestinos y en condiciones de absoluta precariedad e insalubres. A veces se acompaña de tambores y ruidos fuertes para que los gritos no sean escuchados. Se practica sin analgesia, de forma normalmente individual y generalmente varias personas sujetan a las niñas para evitar que se muevan y taparles la boca. Los materiales utilizados son muy variados (cuchillas de afeitar, cuchillas, tijeras...) sin ningún tipo de asepsia. Para cicatrizar las heridas son cubiertas con" o ungüentos fabricados a base de hierbas, ceniza, leche, estiércol..., y se les mantiene con las piernas atadas y separadas del resto de la comunidad durante varios días. Las complicaciones son múltiples no sólo para las propias mujeres en las que, a parte de las múltiples consecuencias psicológicas, se pueden producir infecciones, hemorragias, fusión no intencionada de los labios, problemas urinarios y para la defecación, dolor crónico, cicatrización anómala, problemas menstruales, aumento de infeccciones de transmisisón sexual como el herpes genital y 
el VIH... También genera consecuencias a sus parejas como el miedo a mantener relaciones sexuales por evitar el dolor que producen y aumento de la transmisión de infecciones por traumatismos genitales durante el coito. Así mismo se ve aumentado la morbimortalidad perinatal en proporción directa con la gravedad de la mutilación. Este acto de violencia contra la mujer es en el siglo XXI una práctica todavía muy extendida en cerca de 40 paises, produciéndose cada año alrededor de $3 \mathrm{mi}$ llones de mutilaciones en Africa además de las realizadas en Asia, Oriente Medio y algunos grupos indígenas de américa Latina. Los crecientes movimiento migratorios hacen que ésta sea una realidad en aumento en otras zonas como Australia, Norte de América y Europa en la que se estiman en torno a 180.000 mujeres emigrantes al año desde áreas donde es una práctica habitual. En repuesta a esta realidad y a la obligación y necesidad de detección de estas pacientes así como de las niñas de su entorno que se puedan encontrar en situación de riesgo para padecer una mutilación, se publica en 2015 un Protocolo Común de actuación sanitaria ante la MGF (Ministerio Sanidad, Servicios Sociales e Igualdad), se realizan protocolos en varias Comunidades Autónomas iniciándose el grupo de trabajo en la Comunidad Valenciana en 2016 y presentándose nuestro protocolo de forma oficial por parte de la Consellería en Noviembre de 2016. Junto a dicho protocolo se elabora un mapa de riesgo de MGF en la Comunidad Valenciana desglosado por departamentos y edad, de forma que en el departamento de Elche-Vinalopó se estima que existan un total de 243 mujereres procedentes de áreas donde constituye una práctica común, siendo 188 mayores de 15 años y 15 menores.

Desde la incorporación del Hospital U. Vinalopó a la Comisión de Seguimiento de la
Actuación Sanitaria ante la MGF en la Comunidad Valenciana en Marzo de 2017, llevamos detectados en nuestro departamento 9 casos de mujeres mutiladas a las que se les está ofreciendo un seguimiento y atención integral de toda la patología derivada de su estado de mutilación, así como 5 niñas en situación de especial vulnerabilidad a las que se les están aplicando las medidas y algoritmos de seguimiento por parte de Trabajo social y pediatría de atención primaria. Es necesario que cambiemos nuestra percepción en torno a la MGF como algo lejano y minoritario. Es un problema del que todos somos responsables, visible en nuestro entorno, no tan raro ni tan lejano y sobre el que podemos influir y debemos hacerlo detectando y ayudando a las mujeres que por desgracia ya fueron sometidas a una mutilación y para las que disponemos de múltiples alternativas incluida la cirugía reconstructiva.

Está en nuestras manos intervenir activamente para evitar que se siga cometiendo este tipo de violencia de género hoy en día. Debemos proteger a las niñas en riesgo de mutilación, conociendo los algoritmos de derivación y actuación sanitaria recogidos en el protocolo y declarando las situaciones de riesgo e incluso denunciando el delito en caso de llevarse a cabo en niñas residentes o nacidas en nuestro país. ¡NO MÁS NIÑAS MUTILADAS! 